\title{
LA EUROPA DE ALFONSO X: FECHAS Y PERSONAJES
}

\author{
Carlos Alvar \\ Universidad de Alcalá / IEMSO \\ carlos.alvar@uah.es
}

\begin{abstract}
Alfonso X empieza su reinado en el año 1252, con treinta y un años, y permanecerá en el trono otros tantos años, hasta su muerte en 1284. Así, pues, tres décadas de la segunda mitad del siglo XIII constituyen el período más largo de su actividad política y cultural. No es necesario enumerar, ni hacer hincapié en unos aspectos bien conocidos. Quizás sí que sea conveniente reflexionar acerca del significado de esos años en el ámbito europeo occidental, tan cercano al rey de Castilla y León ${ }^{1}$.

Se podrían establecer, a modo de hitos, unas fechas destacadas, que en sí mismas, dejan apreciar un camino en gran medida sorprendente. El siglo XIII se había iniciado con batallas decisivas, que dejaron paso a un optimismo justificado (o justificable): la conquista de Constantinopla a los bizantinos en la IV Cruzada (1204) y el establecimiento del Imperio Romano, vinculado directamente desde sus inicios con el condado de Flandes, constituyó, sin duda, un alarmante fracaso de los propósitos de las expediciones occidentales en Tierra Santa, pero dio lugar a un gran auge de la República de Venecia y a la mayor proyección de la Casa de Flandes (Runciman 1973). Eran tiempos de optimismo, que duró poco.
\end{abstract}

\footnotetext{
${ }^{*}$ Este trabajo se enmarca en las actividades del proyecto DHuMAR II: From Middle To Golden Age: Translation \& Tradition (Ref.: PY20_00469, proyecto financiado por la Consejería de Transformación Económica, Industria, Conocimiento y Universidades de la Junta de Andalucía y por FEDER Una manera de hacer Europa) y del Proyecto de investigación CM/JIN/2019-004, La implantación de la Cortesía en la Edad Media a través de los testimonios literarios, perteneciente al Contrato Programa Comunidad de Madrid-UAH de Ayudas para la realización de Proyectos de I+D para Jóvenes Investigadores de la Universidad de Alcalá, convocatoria de 2019.

${ }^{1}$ Es evidente que una presentación como ésta no puede entrar en detalles de ningún tipo: simplemente quiero subrayar algunos -no todos- de los aspectos más relevantes, con carácter general.
} 
1. La batalla de Las Navas (1212) aseguraba el predominio de Castilla en la península ibérica a través de la Reconquista (González 1960: I, 981-1071; Alvira Cabrer 2012). Años más tarde, la unión de los reinos de Castilla y León con Fernando III (en 1230) asentaba esa primacía territorial. Las conquistas de Córdoba (1236), Jaén (1245-1246), Sevilla (1248) y Murcia (por el infante don Alfonso, 1243), desplazaron el centro de gravedad del reino hacia el sur, lo que supuso también una reorientación de la política y de la cultura (González 1980-1986: I, 278-394; González Jiménez 2006: 137-170, 171-201 y 203-234). El horizonte se presentaba halagüeño (Ballesteros Beretta 1963; Alvar 1977 y Alvar 1978; González Jiménez 1999: 24-27).
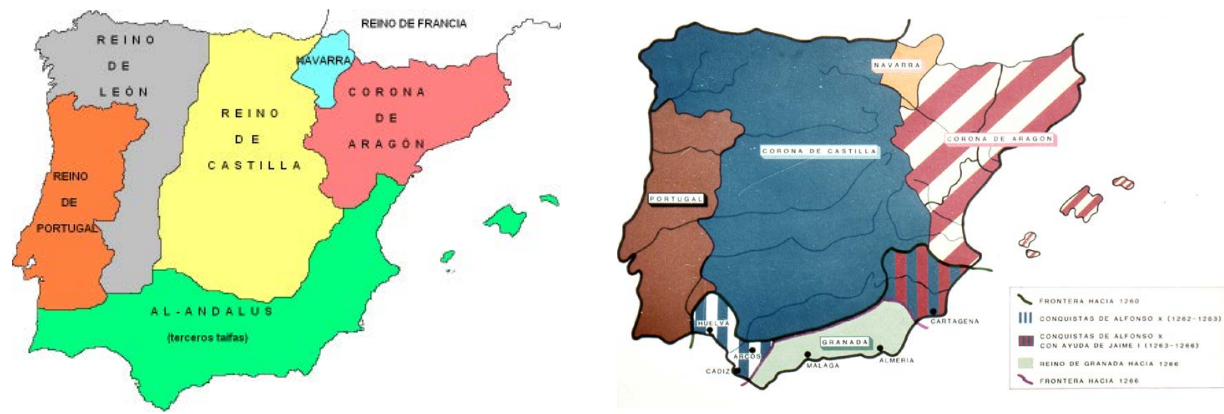

Los reinos peninsulares a comienzos del siglo XIII y en tiempos de Alfonso X.

En línea: <http://socialesmoriles.blogspot.com/2011/01/tema-5-mapas-de-la-peninsula-iberica.html> $<$ http://clio.rediris.es/n32/atlas/057.jpg >

2. El rey de Francia, Felipe Augusto, transformó en muy poco tiempo el mapa político del occidente europeo, debido a tres batallas que establecieron unas nuevas fronteras y limitaron el poder de sus vecinos: la derrota de los aliados en la guerra de los albigenses y la muerte del rey aragonés Pedro II en Muret el año 1213 (Alvira Cabrer 2002); la victoria del heredero francés Luis (VIII) frente a Juan sin Tierra en la batalla de La Roche-aux-Moines, que tuvo lugar el año 1214 (Aurell 2017: 459-489), y la victoria de Felipe Augusto en Bouvines (1214) contra la coalición formada principalmente por el emperador germánico, Otón IV, las tropas inglesas de Juan sin Tierra, las fuerzas de Fernando de Portugal, conde de Flandes y de Hinaut (m. 1233), que fue hecho prisionero y no recobró la libertad hasta 1227 , y el ejército de Rainaud de Dammartin (m. 1227), conde de Boulogne, que murió en la cárcel por este enfrentamiento (Duby 1988).

Las tres grandes victorias del rey francés supusieron la extensión de los dominios de Felipe Augusto por la mitad occidental del actual territorio de Francia, a expensas del rey inglés; por gran parte del norte, en detrimento 
del emperador germánico y de sus aliados; y por el sur, frente a los intereses del rey de Aragón. Esta gran expansión, y sus consecuencias favorables a los capetos, dio a Francia la hegemonía en el occidente europeo y un período de paz que durará hasta el inicio de la Guerra de los Cien Años (1337), causada por la invasión francesa del ducado de Aquitania, aún en poder del rey de Inglaterra (Baldwin 1986; Bradbury 2016). Basta con ver el siguiente mapa, donde quedan de manifiesto la reducción de los dominios del rey inglés o vinculados con él (franja occidental en el mapa de la izquierda) y el amplio territorio ocupado por el rey de Francia y sus feudatarios (prácticamente todo el resto, como se ve a la derecha, exceptuando los pequeños dominos aislados, que se vinculan a la Iglesia y que apenas han variado entre los dos mapas):

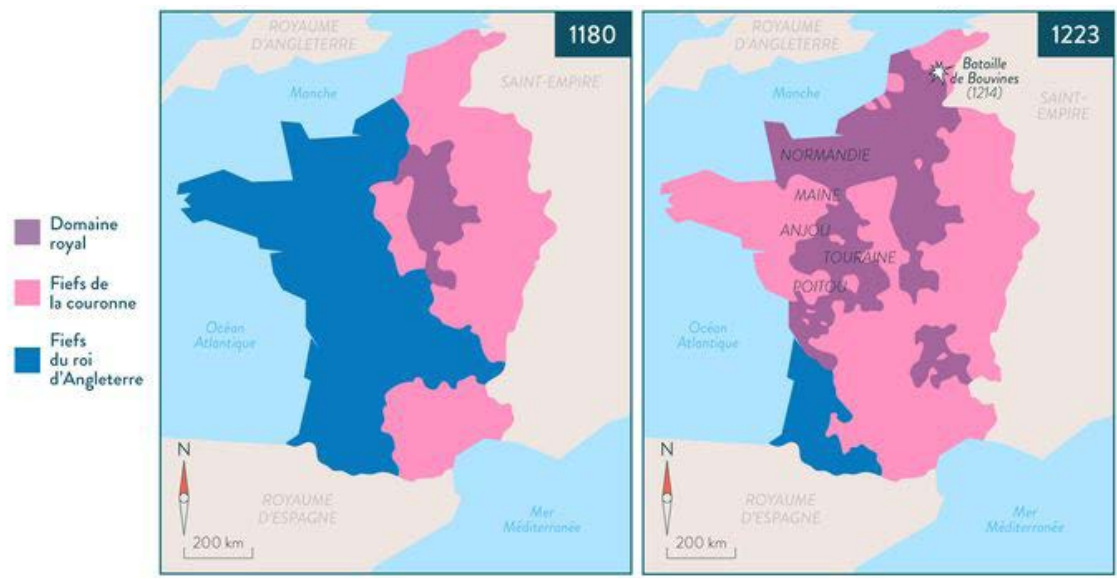

Territorios de Francia y posesiones de Inglaterra en el continente a la llegada de Felipe Augusto al trono (1180) y a su muerte (1223). Los feudos del rey inglés, en color oscuro a la izquierda de la imagen; los feudos del francés, en color claro; los dominios del rey de Francia, en color oscuro en el centro de la primera imagen y casi todo el norte y centro, en la segunda. En línea: $<$ https://i.pinimg.com/736x/77/05/8a/77058a0e59a1b90d23ab412ab740c012.jpg>

3. Una de las consecuencias más destacadas de la victoria francesa en Bouvines fue que el emperador germánico, Otón IV, muy mermado en el número de sus apoyos en tierras alemanas desde 1211 y con muy escasa capacidad política y militar, se viera forzado a abdicar del trono en 1215 en favor de Federico II Hohenstaufen, rey de Sicilia (Abulafia 1990: 90-99; Willemsen 1982; Rill 1995: 223-311; Federico II 2005-2008; Houben 2009).

4. A la edad de tres años, Federico quedó huérfano de su padre, el emperador Enrique VI Hohenstaufen (1197) y, luego, de su madre, Costanza I de 
Sicilia o de Altavilla (Hauteville), en 1198, que había conseguido que el papa Inocencio III -máximo soberano del reino- lo reconociera como legítimo heredero de Sicilia seis meses antes, a la vez que ponía al niño bajo la tutela del pontífice. No fue mucho lo que hizo el papa por su protegido, que fue más un prisionero o un rehén, que un pupilo. Con catorce años es declarado mayor de edad y el año siguiente contrae matrimonio con Constanza de Aragón (1182-1223), unos diez años mayor que él y ya viuda del rey de Hungría. Es el momento en que Inocencio III corona emperador a Otón IV (de familia güelfa), apartando a los Hohenstaufen en la persona del joven Federico, de la dignidad que habían ostentado su padre y su abuelo (gibelinos).

En contra de las promesas que Otón IV había hecho antes de ceñir la corona imperial, no tarda en atacar Sicilia, con la inmediata reacción del papa, que excomulga al invasor, lo que provoca el levantamientos de una parte de la nobleza alemana, que corona rey de Alemania a Federico (1212). Es un momento político muy complicado, ya que la debilidad de Otón IV, emparentado con el rey inglés y aliado suyo, no sólo es hostigada por el papado, sino también por Felipe Augusto, rey de Francia, que desde la cruzada contra los albigenses mantenía fructíferas relaciones con Inocencio III. Así, la batalla de Bouvines allanó el camino de Federico y éste encontró el apoyo de los vencedores, frente a un emperador que estaba cada vez más aislado.

El hábil e inflexible Inocencio III muere en 1216 y es elegido papa Honorio III y dos años más tarde fallece Otón IV. En 1215 Inocencio III había promulgado la V Cruzada (1218-1221), pero fue su sucesor el que se decidió a ponerla en marcha, encomendándola al rey húngaro Andrés II. Triunfos puntuales y poco duraderos hacen de esta cruzada un fracaso y Federico, ausente por voluntad papal (y también por sus propias reticencias, dada la delicada situación política de sus posesiones), tiene que jurar que encabezará una nueva cruzada: sólo así Honorio III accede a coronarlo emperador del Sacro Imperio Romano Germánico en Roma (1220). La promesa no será cumplida hasta 1227, cuando Gregorio IX es elegido papa por la muerte de su predecesor, aunque Federico tiene que interrumpir el desplazamiento de su abundante flota por una epidemia a bordo: es excomulgado. A pesar de todo, el emperador reemprende su expedición a Tierra Santa un año más tarde, entra en Jerusalén gracias a un acuerdo con el sultán de Egipto, al-Kamil, lo que le vale importantes críticas de sus aliados y de la Iglesia, se corona rey de Jerusalén y a continuación se dirige a San Juan de Acre (1229) (Runciman 1973: III, 131-165).

En Italia, Federico II se tiene que ocupar a su regreso de las continuas revueltas de las ciudades-estado del norte, proclives al poder del papa, más que 
al del emperador, y vence a su hijo Enrique (1235)²; el mismo año se casa con Isabel de Inglaterra, hija de Juan sin Tierra y hermana del nuevo rey inglés, Enrique III (1207-1272, rey desde 1216). El nombramiento de su hijo Enzo ${ }^{3}$ como rey de Cerdeña vuelve a provocar la cólera del papa, que se veía amenazado no sólo por las victorias imperiales en Lombardía y por el matrimonio con Isabel: es excomulgado de nuevo (1239). La muerte del papa dos años más tarde, cuando ya había convocado un concilio para deponer a Federico, y la sucesión de dos pontífices en un breve plazo de tiempo, permite cierta paz entre los contendientes; pero en 1243 un nuevo papa, Inocencio IV, reúne un concilio en Lyon, depone al emperador y proclama una cruzada contra el mismo, lo que da lugar a levantamientos y conspiraciones de los güelfos en Alemania, Lombardía y Sicilia, apoyados por gibelinos descontentos. La derrota de Parma (1248), frente a la Liga Lombarda, y frente a fuerzas de Milán, Mantua, Ferrara y Piacenza, fue sin duda el final de las aspiraciones del emperador en los territorios del norte italiano, además de la causa de una profunda y duradera inestabilidad política en las ciudades toscanas, hasta entonces de marcada tendencia gibelina. Federico II murió en 1250 por causas naturales (Contini 1960: I, 43-185 y II, 799-819; Folena 1965: 271-347; Beretta Spampinato 1980: 387-425; Roncaglia 1982: 33-147; Varvaro 1987: 7999; Bruni 1990: 211-273; Antonelli 1994: 309-323; Panvini 1994; Brugnolo 1995: 265-337; Delle Donne 2019).

Su hijo Conrado IV de Alemania (1237-1254; rey de Sicilia, 1250-1254) murió excomulgado cuando acudía a imponerse en sus territorios italianos. Manfredo, hijo ilegítimo de Federico II, fue regente de Sicilia (1254-1266); se negó a entregar el reino a Inocencio IV, que se lo reclamaba como señor natural; fue excomulgado por Alejandro IV; Urbano IV intentó frenar su expansión por el norte de Italia y para ello pidió el apoyo de Carlos I de Anjou (hijo póstumo del rey francés Luis VIII y hermano de Luis IX), al que ofreció el reino de Sicilia: en la batalla de Benevento (1266) muere Manfredo y Sicilia queda en manos de los angevinos (Bastard 1972: 231-256 y 1973: 95-117). Enzo, hijo ilegítimo, nombrado rey de Cerdeña por Federico II, fue hecho prisionero por el ejército de Bolonia en la batalla de Fossalta (1249) y murió sin recobrar la libertad (1272). Enrique Otón, hijo de Federico y de su tercera esposa, Isabel de Inglaterra, murió en 1253, con quince años, sin haber ascendido al trono de Jerusalén, para el que había sido nombrado. Conradino, hijo de Conrado IV y rey de Sicilia (1254-1268), fue derrotado por

\footnotetext{
${ }^{2}$ Enrique era el primogénito, hijo de Federico II y Constanza de Aragón; murió prisionero en 1242.

${ }^{3}$ También llamado Enrique, era hijo ilegítimo y para distinguirlo del primogénito se suele utilizar su hipocorístico Enzo (en latín Encius o Henthius, del alemán Heinz).
} 
Carlos de Anjou en Tagliacozzo (1268), que ordenó que fuera decapitado en Nápoles: el joven Conradino apenas tenía dieciséis años. Allí acabó la rama directa masculina de los Hohenstaufen (De Bartholomaeis 1931).

Eran tiempos turbulentos y no faltaron personajes dispuestos a echar leña al fuego.

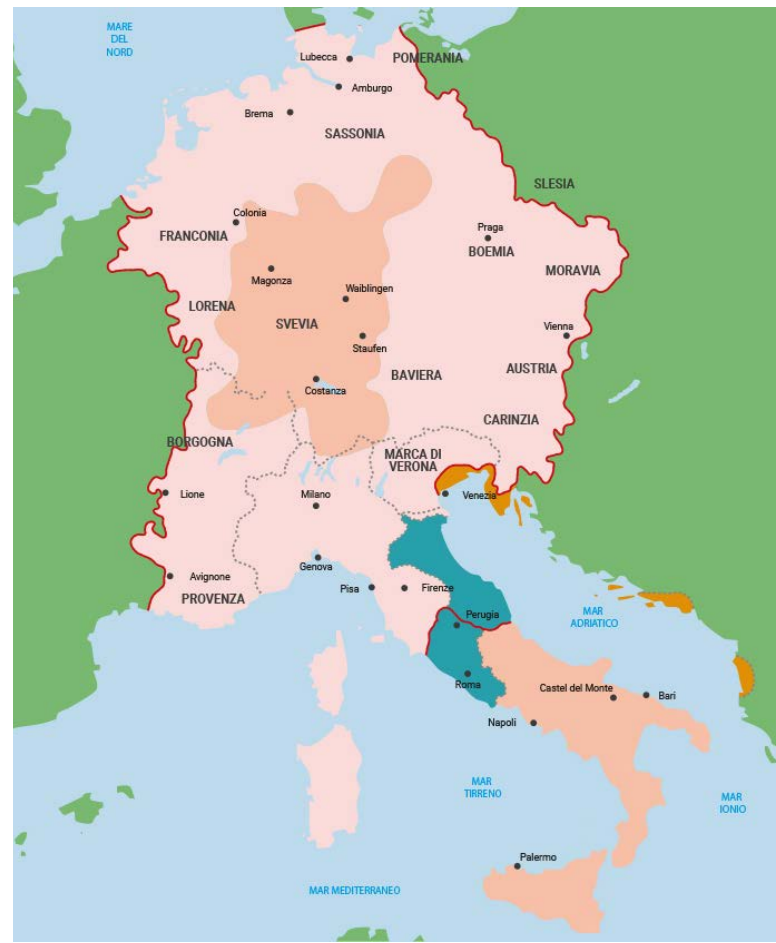

Imperio de Federico II. En color claro, los territorios feudatarios; sombreadas, las posesiones de emperador; el centro se marca en color oscuro el Patrimonio de S. Pedro.

$<$ https://www.hubscuola.it/cdi/lab_cartografia/v1/11_impero_di_federico_ii/assets/img/intro/intro.jpg >

5. Uno de esos personajes fue Carlos I de Anjou (1226 o 1227-1285), cuya vida estuvo estrechamente ligada al devenir histórico de la Casa de los Hohenstaufen y, en definitiva, del Imperio (Jordan 1909: 370-602; Jordan 1939: 347-421; Runciman 1961: 69-198; Asperti 1995; Grenon 2012). Casado con la heredera del condado de Provenza, Beatriz (1246), impuso en los dominios de su esposa el modelo político y administrativo del reino de Francia, para lo que tuvo que apoyarse en nobles y caballeros llegados de las tierras de su hermano Luis IX, frente a la dura resistencia de numerosos grandes señores feudales, que se sintieron marginados ante los privilegios concedidos a los recién llegados. Las consecuencias fueron continuas revueltas en 
las ciudades más importantes y en otras localidades menores, que no fueron sofocadas -y no por completo- hasta 1252. La actividad de Carlos de Anjou continuó por el norte de Italia, con el apoyo del rey de Francia y del Papado: ante los éxitos obtenidos y el creciente poderío político y militar del conde de Provenza en territorios de signo gibelino, Urbano IV vio la posibilidad de limitar las pretensiones de Manfredo, hijo ilegítimo de Federico II y rey de Sicilia, y solicita el apoyo del belicoso Carlos, que no tarda en ser elegido Senador de Roma. Las fuerzas del conde de Provenza se centran ahora en la península itálica, momento aprovechado por Manfredo y Pedro III de Aragón (casado con Constanza de Hohenstaufen, hija y heredera de Manfredo) para atizar nuevas revueltas. La muerte de Urbano IV (1264) no supuso un cambio radical en la alianza de Francia con el Papado, ni la retirada del apoyo del nuevo papa, Clemente IV, a Carlos da Anjou: al fin y al cabo, Clemente era francés, como Urbano, y la alianza con Luis IX había facilitado el control al Emperador en Provenza y el norte de Italia; por otra parte, el influjo francés se había asentado más aún en las tierras meridionales. En 1265, Carlos de Anjou fue recibido como Senador de Roma (21 de junio), una semana más tarde, fue nombrado rey de Sicilia y coronado pocos meses más tarde en San Pedro de Roma: la agresión papal contra Manfredo era evidente, y éste no tardó en responder, enfrentándose en Benevento (en febrero de 1266) al Angevino, que contaba con el apoyo de los güelfos del norte de Italia. La muerte de Manfredo deja Sicilia en manos francesas, como ya hemos visto, y Carlos, nuevo rey y nueva dinastía, impone el modelo francés, como había hecho antes en su condado de Provenza y, en consecuencia, se repitieron los privilegios de unos y las revueltas de los otros, agravadas por los beneficios concedidos a los mercaderes toscanos en detrimento de los genoveses y pisanos, ampliamente establecidos en la isla.

El malestar fue aprovechado por Conradino Hohenstaufen para unir a los gibelinos y recuperar gran parte de Sicilia, del sur de la península itálica y algunos territorios en el norte. Carlos de Anjou se iba debilitando con los abandonos y defecciones de sus partidarios: uno de los más destacados será el infante don Enrique de Castilla, hermano de Alfonso X (Riquer 2016) ${ }^{4}$.

\footnotetext{
${ }^{4}$ El infante don Enrique, hijo de Fernando III y de Beatriz de Suabia, nació en 1230. Tras rebelarse contra su hermano el rey Alfonso, huyó a Aragón e Inglaterra, posiblemente, y, por fin, hizo fortuna en Túnez (1259-1266); luego, acudió a Italia para dar apoyo económico y militar a Carlos de Anjou; fue nombrado Senador de Roma y al no lograr que el papa lo hiciera rey de Cerdeña porque Carlos de Anjou lo impidió en beneficio propio, lo abandonó y se pasó al lado de Conradino: la derrota de Tagliacozzo (1268) supuso la prisión de don Enrique durante veintitrés años, hasta 1291, fecha en la que pudo regresar a Castilla, no sin antes haber ido a Túnez, donde desempeñó el cargo de embajador ante el rey aragonés, Jaime II. Ya en Castilla, causó escándalo por su «alegre» y «bulliciosa» forma de vida, a pesar de su avan-
} 
Consciente del peligro, Carlos actúa contra los rebeldes cada vez con mayor violencia y crueldad y, finalmente, la victoria inesperada en Tagliacozzo (1268) le deja el camino expedito para ejecutar a cuantos miembros de la nobleza se habían levantado contra él, para privar de bienes a los demás y para reemplazar a todos con sus partidarios al frente de las nuevas posesiones del sur de Italia y de Sicilia. Por si fuera poco, la Iglesia también aprovechó para ir contra cátaros y valdenses que se habían refugiado en el norte de Italia tras la cruzada albigense: la Inquisición se mostró implacable con ellos.

A continuación, Carlos decidió imponer su presencia en el Mediterráneo oriental, y para ello convenció a María de Antioquía para que le vendiera el título de rey de Jerusalén (1277). La situación política poco estable en el norte de Italia y en Sicilia, y las preocupaciones en Tierra Santa y territorios del Imperio de Oriente llevaron a Carlos de Anjou a establecer la corte en Nápoles.

No tardan en sucederse las derrotas en el Mediterráneo, pero sin duda, una de las más relevantes fue la provocada por la rebelión siciliana conocida como «Vísperas sicilianas» (1282), impulsada por el relevante médico Juan de Prócida, muy cercano a los Hohenstaufen, que contaba, además, con el apoyo de Aragón, Génova y Bizancio. El resultado del levantamiento fue la destrucción de la flota de Carlos de Anjou en el puerto de Mesina, a la vez que fueron aniquilados casi todos los franceses de la isla (Runciman 1961). Pocos meses más tarde, el mismo año, Pedro III de Aragón fue coronado rey de Sicilia.

Las derrotas navales de las tropas angevinas en Malta (1283) y en el golfo de Nápoles (1284) no hicieron sino corroborar el debilitamiento de Carlos de Anjou, que no tardaría en morir (1285), y el triunfo aragonés en el Mediterráneo, especialmente gracias a un nuevo personaje, no menos significativo del momento, Roger de Lauria, marino de origen calabrés refugiado en la Corona de Aragón, al servicio de Pedro de III.

\footnotetext{
zada edad. Al morir su sobrino, el rey Sancho IV (1295), se hizo cargo del heredero, Fernando (IV), cuya minoría iba a ser larga, pues apenas contaba nueve años cuando falleció su padre. En 1303, don Enrique, con 73 años, conspiró junto al infante don Juan Manuel, sobrino suyo, y otros altos nobles, para derrocar al joven rey y repartirse sus dominios; naturalmente, no faltó el impulso del rey aragonés; a pesar de la gravedad de esta reunión (Roa y Ariza), más bien parece que se tratara de un encuentro de despedida de viejos camaradas y compañeros, a juzgar por el séquito de juglares que acompañaba a todos ellos. Pocos días más tarde murió el infante don Enrique.
} 


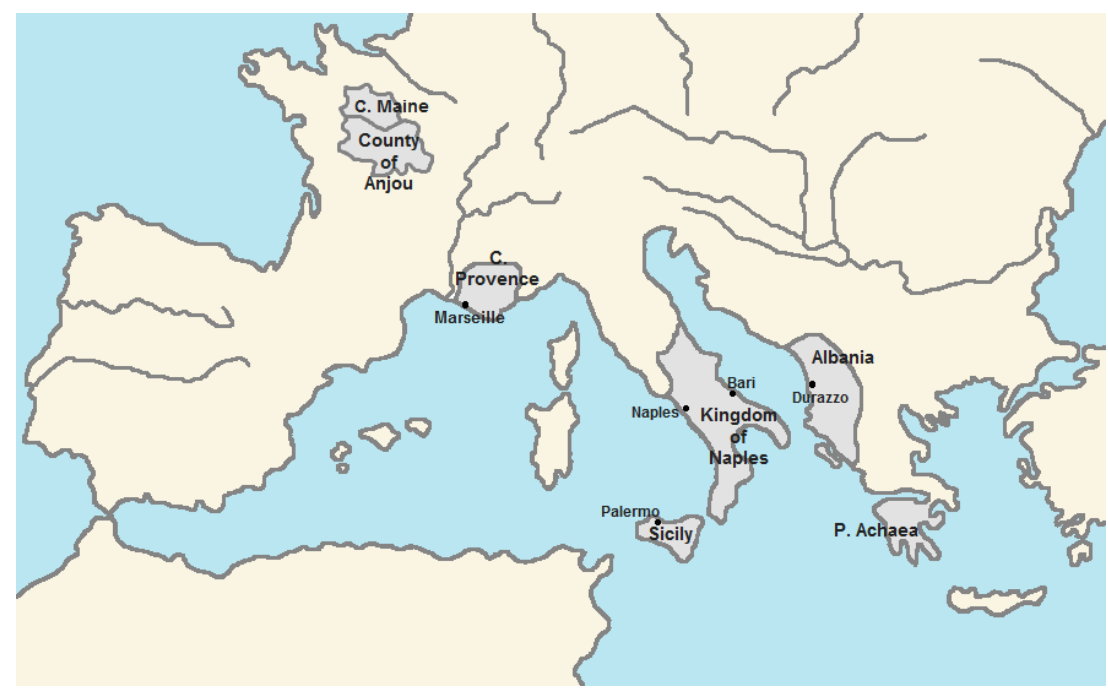

Dominios de Carlos I de Anjou (1270). Tomado de Abulafia 2014: 282-283.

$<$ https://upload.wikimedia.org/wikipedia/en/2/2d/CharlesofAnjouempire.png $>$

6. Tras la muerte de Pedro II de Aragón en la batalla de Muret (1213), heredó el reino su hijo Jaime I (1208, 1213-1276), que el mismo año quedó huérfano de madre, la reina María, de la que heredó el señorío de Montpellier. Conquistó el reino de Mallorca en 1229, el de Valencia en 1238 y apaciguó definitivamente el reino de Murcia (1265-1266), que había sido conquistado por el infante don Alfonso de Castilla (1243), al que cedió el poder de acuerdo con lo establecido en el tratado de Almizra (1244). Por el tratado de Corbeil (1258) renunció a sus derechos sobre los territorios del sur de Francia en favor del rey Luis IX, que por su parte se abstendría de cualquier demanda sobre los condados de la antigua Marca Hispánica, conquistada por Carlomagno ${ }^{5}$. Quedaba así casi totalmente configurado el territorio de la Corona de Aragón, que después quedaría dividido en Aragón y Valencia, por una parte, y Mallorca, por otra. En 1252 su hija Violante se casó con el rey Alfonso X (Dufourcq 1979-1982; Soldevila 1980; Sesma 2000; Villacañas 2003; Belenguer 2008; Cingolani 2008).

\footnotetext{
${ }^{5}$ El propio rey Jaime I escribe una crónica (Libre dels feyts, 1244 y 1274) del máximo interés para conocer gran parte de sus conquistas y de su actividad política, aunque se «olvide» del tratado de Corbeil. Con esta crónica se inicia la serie de las cuatro grandes crónicas catalanas: además de la de Jaime I hay que añadir la de Bernat Desclot, para el reinado de Pedro III, acabada en 1288; la de Ramon Muntaner, que se ocupa de la expansión mediterránea, como jefe de almogávares a las órdenes de Roger de Flor, acabada en 1325; y la de Pedro IV, el Ceremonioso, que dio término a la segunda redacción de la crónica de su reinado antes de que acabara el año 1386 (Soldevila 1971).
} 
Muy distinto fue el talante de su hijo y heredero Pedro III (1240, 12761285), conocido como «el Grande»: bastará considerar su matrimonio con Constanza (1262), hija de Manfredo, muerto en la batalla de Benevento contra Carlos de Anjou (1266); la ejecución de Conradino, después de la batalla de Tagliacozzo (1268), puso fin a la rama directa masculina de los Hohenstaufen, y, así, Constanza se convirtió en la heredera de los derechos familiares sobre el reino de Sicilia. Conquistadas Valencia y las Islas Baleares, el matrimonio de Pedro III abría el dominio del Mediterráneo a los aragoneses, y la tentación siciliana era evidente, igual que el peligro que supondría el dominio de la isla para los intereses angevinos y papales en el sur de Italia. Además, la ocupación de las tierras meridionales por parte de los franceses no estaba totalmente lograda y la actitud violenta de Carlos de Anjou hizo que una parte de la nobleza leal a los Hohenstaufen se refugiara en el reino de Aragón y agitara, con la connivencia del rey Pedro III, las revueltas de la población en el sur de Francia y en Sicilia contra el usurpador: tal fue el caso de Juan de Prócida, Roger de Lauria y de Conrado Lanza. Las Vísperas sicilianas (1282), con la coronación de Pedro III como rey de Sicilia (y la consiguiente excomunión papal), marcan el inicio del ocaso de Carlos de Anjou y del auge aragonés en el Mediterráneo (Soldevila 1950-1962; Riquer 1964; Lacarra 1990: 93-316; Cingolani 2010; Espadaler 2011: 183-198 y Espadaler 2021).

7. Mientras tanto, el reino de Portugal estaba sumergido en un profundo conflicto con la Iglesia, que afectó a los sucesivos monarcas, al menos desde tiempos de Sancho I (1154, 1185-1211); este rey y sus descendientes Afonso II, Sancho II y Afonso III fueron excomulgados y el reino puesto bajo interdicto papal en reiteradas ocasiones. La razón fue el poder alcanzado por los obispos de las sedes principales (Braga, Coimbra, Oporto y, luego, Lisboa) debido al vasallaje al Papa del naciente reino de Afonso I Henriques (1143) para evitar problemas con el poderoso Alfonso VII de León y Castilla (1105, 1126-1157), proclamado «emperador de toda España» en 1135, y para tener la protección de la Iglesia frente a los belicosos nobles. El continuo esfuerzo de los reyes portugueses por emanciparse del vasallaje eclesiástico fue fuente de innumerables conflictos con la Iglesia, que no dudó en intervenir en cuestiones dinásticas, provocando o alimentando las graves guerras civiles y los continuos alejamientos del seno religioso. La situación se agravaba con la importante presencia de las órdenes militares (Temple, San Juan) como fundamento de la Reconquista, que a cambio de su participación en los conflictos armados contra los musulmanes obtuvieron considerables beneficios en las tierras conquistadas. En el fondo, se reproducía en Portugal una situación 
semejante a la de Italia, generada por el choque de las ideas teocráticas del papa Gregorio VII (1073-1085) con la creciente aplicación del Derecho romano en la sociedad civil que se produjo en el siglo XIII (Serrão 1977; Herculano 1980; Mattoso 1993).

Afonso III (1210, 1248-1279) era conde consorte de Boulogne-sur-mer por su matrimonio con Matilde II (1235) cuando fue reclamado por la Iglesia para ocupar el trono portugués, tras los levantamientos que se habían producido bajo el reinado de su hermano Sancho II; el papa Inocencio IV había excomulgado al monarca por no cumplir los acuerdos y por continuar con los intentos de su padre para reducir el poder eclesiástico: en el I Concilio de Lyon (1245) dictó sentencia contra el rey y, también, contra el emperador Federico II.

La reina Blanca de Castilla, madre de Luis IX de Francia, y tía de ambos contendientes portugueses, se inclinó hacia el conde de Boulogne, que abdicó, repudió a la condesa Matilde y regresó a Portugal donde mantuvo las hostilidades contra su hermano hasta que este murió en Toledo (1248). Sin embargo, el acercamiento a los intereses de la Iglesia no impidió que él también fuera excomulgado - por Clemente IV, en 1268-y que el interdicto papal recayera sobre el reino, con Gregorio X, en 1277: las reformas legales que intentó impulsar, apoyándose en parte de la nobleza y en el pueblo, habían chocado - una vez más- con la oposición eclesiástica.

A pesar de los conflictos con Castilla en el siglo XIII, el Algarve quedó definitivamente incorporado al reino de Portugal (1249) y las fronteras apenas sufrieron alteraciones desde la muerte de Afonso III (Ramos: 2011: 489-509; Alvar 2020: 71-90).

8. Una serie de azares -obviamente fortuitos- hizo que un conde de Champaña y de Brie acabara siendo rey de Navarra: Thibaut IV, el Trovador (12011253), sería alzado rey con el nombre de Teobaldo $\mathrm{I}^{6}$. A su muerte heredó el

\footnotetext{
${ }^{6}$ No me ocupo de él por extenso, ya que su reinado apenas coincide cronológicamente con el de Alfonso X. La muerte de Henri II de Champaña (1166-1197) en la III Cruzada, sin hijos varones, hizo que el sucesor fuera su hermano Thibaut (nacido en 1179); así Thibaut se convirtió en el tercer conde de Champaña con este nombre. En 1199 se casó con Blanca de Navarra, hija de Sancho VI y hermana del rey navarro Sancho VII. Iba a emprender la IV Cruzada cuando murió repentinamente (1201): tenía una hija de pocos meses, y menos de una semana después de la muerte del conde, nació un niño, que sería sucesor de su padre en Champaña, con el nombre de Thibaut IV. El rey Felipe Augusto se convirtió en protector de la madre y los niños (1209), que de este modo se educaron en la corte y, más tarde se convirtieron en sus vasallos, lo que frenaba las pretensiones de otros nobles que pretendían quedarse con el rico condado de Champaña y Brie. Como vasallo del nuevo rey francés, Luis VIII, participó en acciones militares diversas contra los ingleses y contra los albigenses de Aviñón (1226), aunque no permaneció al lado del rey hasta la caída de la ciudad: la defección fue causa del enojo del monarca contra Thibaut IV, pero la muerte de Luis VIII poco tiempo después evitó represalias, aunque no pudo impedir que se expandiera la sospecha de que
} 
trono navarro su hijo Teobaldo II (Thibaut V, 1239, 1253-1270), cuya minoría de edad (hasta 1256) fue guiada por la reina viuda, Margarita de Borbón, mujer de sabiduría y prudencia políticas, y tutelada por el rey aragonés, Jaime I, que constituirá uno de los referentes de su política. El matrimonio del joven rey de Navarra en 1255 con Isabel de Francia (1239-1271), hija de Luis IX, marcó de forma definitiva la inclinación hacia el modelo de gobierno impulsado por su suegro: no sólo en la diplomacia con Aragón y Castilla, o en los pactos y acuerdos alcanzados con los nobles y las villas, sino también en el apoyo a la burguesía y al comercio mediante privilegios y exenciones tributarias. La influencia de Luis IX fue de especial importancia en la relación con la Iglesia: Teobaldo II fue ungido rey en 1257 y coronado por el papa Alejandro IV dos años más tarde, ritos ajenos a la tradición navarra, que justificaban su derecho divino al trono y aseguraban el apoyo eclesiástico frente a los pretendientes de las posesiones del joven rey tanto en la península ibérica, como en el territorio francés. Así, no extraña que ayude a Carlos de Anjou en Sicilia, recién arrebatada a los Hohenstaufen (1269), y que el año siguiente participe en la VIII Cruzada al lado de Luis IX: tras la muerte del rey francés en Túnez, a causa de la disentería, Teobaldo II continuó la campaña militar con Carlos de Anjou en las tierras norteafricanas, aunque por poco tiempo, pues infectado por la peste, murió en el mismo año de 1270 en Sicilia (Arbois de Jubainville 1863-1865: IV 1, 2 y V; Lacarra 1972: II, 163-192; Alvar 1977: 281-283; García Arancón 1985, 1986; García Arancón 2018b).

\section{Epílogo}

Por breve que sea, el panorama que he mostrado deja de manifiesto una serie de hechos bien conocidos para los estudiosos de la Historia de Europa occidental durante la Edad Media

La continuidad de las Cruzadas, clave para el ejercicio del poder por parte de los Papas, que utilizaron con frecuencia las ausencias y las promesas incumplidas para infligir severos castigos espirituales a los reyes y a los

en la muerte había intervenido el conde, envenenando a su señor, pues el champañés -se dijo despuésestaba enamorado de la reina francesa, Blanca de Castilla. En fin, al morir Sancho VII de Navarra sin herederos legítimos (1234), la corona recayó en Thibaut IV, sobrino del navarro, pues era hijo de Blanca de Navarra (1177-1229), hermana de Sancho VII y también de Berenguela de Navarra (1165-1230), la esposa del rey inglés Ricardo Corazón de León. Teobaldo I de Navarra (o Thibaut IV de Champaña) fue a la cruzada en 1239 , tras varios aplazamientos, pero las tensiones, que ya se habían manifestado antes de emprender la expedición, hicieron que fracasaran los propósitos. De regreso, se mantuvo leal al rey de Francia en sus guerras con Inglaterra. Murió en 1253 (Arbois de Jubainville 1863-1865: IV 1, 2 y V; Lacarra 1972: II, 131-162; Runciman 1973: III, 201-206; Alvar 1977: 277-281; Fortún Pérez de Ciriza 1987: 315-341; Martín Duque/Ramírez Vaquero 1990: 25-38; García Arancón 2018a). 
habitantes de sus reinos. El señorío de Venecia supo aprovechar las oportunidades comerciales que surgían de los continuos enfrentamientos y las treguas consiguientes.

La expansión de la Corona de Castilla y León y su afianzamiento como centro del poder peninsular.

La expansión de Francia, en detrimento de Inglaterra, del Imperio y de Aragón.

El declive del Imperio y la desaparición casi total de los Hohenstaufen, debido a los continuos enfrentamientos con la Iglesia.

El auge de la Iglesia, apoyada por Francia, que encontró en Carlos de Anjou un destacado ejecutor de sus deseos (y de sus vencidos), especialmente en el condado de Provenza y en el reino de Sicilia.

La Corona de Aragón, desposeída de parte de sus territorios del sur de Francia, se vio obligada a buscar la salida hacia el Mediterráneo, lo que le permitió una significativa expansión hacia las islas del Levante, en detrimento de las pretensiones de Carlos de Anjou y de la Iglesia.

Por su parte, Portugal mantiene un largo conflicto con la Iglesia y, otro, con León y Castilla.

En fin, el reino de Navarra ha elegido como rey a un conde de Champaña, lo que la ha vinculado directamente a los intereses de Francia y de sus aliados, la Iglesia y Carlos de Anjou.

Las relaciones políticas son complicadas, difíciles, y están agravadas, con frecuencia, por los vínculos matrimoniales y otros lazos de parentesco, que no siempre sirven para atenuar los conflictos, antes al contrario, llegan a enconarlos más aún.

Lo más sorprendente es que, a pesar de las incesantes hostilidades de unos y otros, florece con vigor la literatura; en especial, la que puede servir de propaganda ideológica, pero no sólo: la historiografía, que legitima el poder; la narrativa de ficción, que contribuye a crear un modelo político; la poesía lírica que elabora un determinado tipo de ética en la corte.

La protección de poetas, e intelectuales en general, no es un divertimento, sino una necesidad para el cumplimiento de los intereses del rey. Y son los reyes los primeros en practicar e impulsar la actividad literaria, aunque no son los únicos, pues el desarrollo de las ciudades y el progreso de las universidades crean nuevos modelos de producción literaria y, con ellos, nuevos géneros.

El occidente europeo ha fijado sus fronteras a lo largo del siglo XIII. Es una muestra más de la nueva identidad política y social que se empieza a manifestar, a la vez que la unidad tan deseada por Carlomagno se fragmenta. 
Y la figura del autor se impondrá a la anonimia y tiranía formal del género literario.

A finales del siglo, se multiplican los disturbios locales, los enfrentamientos entre facciones opuestas, las guerras civiles, nuevos síntomas de los cambios que se están produciendo en una sociedad, la europea, que difícilmente puede asumir las calamidades derivadas del turbulento siglo vivido: las consecuencias serán obvias en el siglo XIV.

También Alfonso X vivió esas tensiones y padeció la guerra civil hasta el último momento de su reinado, aunque parezca imposible al contemplar la extraordinaria labor que realizó.

\section{Referencias bibliográficas}

Abulafia, David (1990), Federico II. Un imperatore medievale. Torino: Einaudi.

Alvar, Carlos (1977), La poesía trovadoresca en España y Portugal. Madrid: CUPSA.

Alvar, Carlos (1978), Textos trovadorescos sobre España y Portugal. Madrid: CUPSA.

Alvar, Carlos (2020), «Las cantigas de amor y de amigo, revisitadas», en I. Barros Dias, M. Santos Alpalhão y M. E. Pina (eds.), O Medievalismo no século XXI. Berlin/Bern/Bruxelles: Peter Lang, pp. 71-90.

Alvira CABrer, Martín (2002), 12 de Septiembre de 1213. El Jueves de Muret. Barcelona: Universitat de Barcelona.

Alvira CABrer, Martín (2012), Las Navas de Tolosa, 1212: Idea, liturgia y memoria de la batalla. Madrid: Sílex.

ANTONELLI, Roberto (1994), «La scuola poetica siciliana alla corte di Federico II», en P. Toubert y A. Paravicini Bagliani (eds.), Federico II e le scienze. Palermo: Selerio, pp. 309-323.

Arbois de Jubainville, Henri d'(1863-1865), Histoire des ducs et des comtes de Champagne, IV. 1, 2 y V. Paris: Thorin.

Asperti, Stefano (1995), Carlo I d'Angiò e i trovatori. Componenti «provenzali» e angioine nella tradizione manoscritta della lirica trobadorica. Ravenna: Longo Editori.

Aurell, Martin (2017), «La bataille de la Roche-aux-Moines. Jean sans Terre et la prétendue traîtrise des Poitevins», en Comptes-rendus des séances de l'Académie des inscriptions et belles-lettres. Paris: Académie des inscriptions et belles-lettres, pp. 459-489. 
BaLdwin, John W. (1986), The Government of Philip Augustus. Foundations of French Royal Power in the Middle Ages. Berkeley: University of California Press.

Ballesteros Beretta, Antonio (1963), Alfonso X el Sabio. Barcelona/Madrid, Salvat Editores.

BASTARD, Antoine de (1972), «La bataille de Bénévent (1266) et la mort de Manfred», Revue des langues romanes, 80, pp. 231-256.

BASTARD, Antoine de (1973), «La bataille de Bénévent (1266)», Revue des langues romanes, 81 , pp. 95-117.

Belenguer, Ernest (2008), Jaime I y su reinado. Lérida: Milenio.

Beretta Spampinato, Margherita (1980), «La scuola poetica siciliana», en Storia della Sicilia. IV. Palermo: Società Editoriale Storia di Napoli e della Sicilia, pp. 387-425.

Bradbury, Jim (2016), Philip Augustus, King of France 1180-1223. Abingdon-on-Thames: Routledge \& CRC Press.

BRugnolo, Furio (1995), «La scuola poetica siciliana», en E. Malato (dir.), Storia della letteratura italiana. I. Dalle origini a Dante. Roma: Salerno Edit., pp. 265-337.

BRUNI, Francesco (1990), «La cultura alla corte di Federico II e la lirica siciliana», en G. Bàrberi Squarotti (dir.), Storia della civiltà letteraria italiana. I. Dalle origini al Trecento. Torino: UTET, pp. 211-273.

Cingolani, Stefano Maria (2008), Historia y mito del rey Jaime I de Aragón. Barcelona: Edhasa.

Cingolani, Stefano Maria (2010), Pere el Gran: Vida, actes i paraula. Barcelona: Base.

Contini, Gianfranco (ed.) (1960), Poeti del Duecento. Milano/Napoli: R. Ricciardi.

De Bartholomaeis, Vincenzo (1931), Poesie provenzali storiche relative all'Italia. Roma: Istituto Storico Italiano. 2 vols.

Delle Donne, Fulvio (2019), La porta del sapere. Cultura alla corte di Federico II di Svevia. Roma: Carocci.

Duby, Georges (1988), El domingo de Bouvines. Madrid:Alianza Editorial,.

DufourcQ, Charles Emmanuel (ed.) (1979-1982), Jaime I y su época. X Congreso de Historia de la corona de Aragón. Zaragoza: Institución Fernando el Católico. 3 vols.

ESPADALER, Antón M. (2011), «La cort del pus onrat rei: Jacques I ${ }^{\text {er }}$ d'Aragon et le roman de Jaufré», Revue des Langues Romanes, 115:1, pp. 183-198.

Federico II. Enciclopedia fridericiana (2005-2008). Roma: Istituto dell'Enciclopedia italiana. 3 vols. 
Folena, Gianfranco (1965), «Cultura e poesia dei siciliani», en E. Cecchi y N. Sapegno (dirs.), Storia della letteratura italiana, I. Le origini e il Duecento. Milano: Garzanti, pp. 271-347.

Fortún PÉrez de Ciriza, Luis Javier (1987), Sancho VII el Fuerte (11941234). Pamplona: Mintzoa.

García Arancón, M. ${ }^{a}$ Raquel (1985), Teobaldo II de Navarra, 1253-1270. Gobierno de la monarquía y recursos financieros. Pamplona: Gobierno de Navarra.

García Arancón, M. ${ }^{a}$ Raquel (1986), Reyes de Navarra. Teobaldo II. Pamplona: Mintzoa.

García Arancón, M. ${ }^{a}$ Raquel (2018a), «Teobaldo I», en Real Academia de la Historia, Diccionario Biográfico electrónico (DB-e). En línea: $<\mathrm{https}$ :// dbe.rah.es/biografias/8601/teobaldo-i $>$, [consulta: 1/10/2021].

García Arancón, M. ${ }^{a}$ Raquel (2018b), «Teobaldo II», en RAH, Diccionario Biográfico electrónico (DB-e). En línea: $<$ https://dbe.rah.es/biografias/8603/teobaldo-ii >, [consulta: 1/10/2021].

GonZÁLEZ JiMÉNEZ, Manuel (1999), Alfonso X (1252-1284). $2^{\mathrm{a}}$ ed. corregida y aumentada. Burgos: Editorial La Olmeda/Diputación Provincial de Palencia.

González JimÉnez, Manuel (2006), Fernando III el Santo. El rey que marcó el destino de España. Sevilla: Fundación José Manuel Lara.

González, Julio (1960), El Reino de Castilla en la época de Alfonso VIII. Madrid: CSIC. 3 vols.

GonzáLEZ, Julio (1980-1986), Reinado y diplomas de Fernando III. Córdoba:

Monte de Piedad y Caja de Ahorros de Córdoba. 3 vols.

Grenon, Michel (2012), Charles d'Anjou, frère conquérant de saint Louis. Paris: L'Harmattan.

Herculano, Alexandre (1980), História de Portugal. Vol. I. Lisboa: Ed. Bertrand.

Houben, Hubert (2009), Federico II. Imperatore, uomo, mito. Bologna: Il Mulino.

Jaufré (2021). Antón M. Espadaler (trad.). Barcelona: Barcino.

JORDAN, Edouard (1909), Les origines de la domination angevine. Paris : Libr. Alphonse Picard fils.

JoRDAN, Edouard (1939), L'Allemagne et l'Italie aux XII et XIII ${ }^{e}$ siècles. Paris: PUF.

LACARRA, José María (1972), Historia política del reino de Navarra (desde sus orígenes hasta su incorporación a Castilla). Vol. II. Pamplona: Edit. Aranzadi. 
LaCARra, José María (1990), «La Corona de Aragón. 1213-1336», en J. M. ${ }^{a}$ Jover Zamora (dir.), Historia de España de Menéndez Pidal, t. XIII/2. Madrid: Espasa-Calpe, pp. 93-316.

Martín Duque, Angel J. y Eloísa Ramírez Vaquero (1990), «El reino de

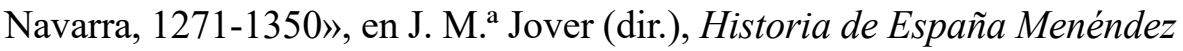
Pidal, XIII/2. Madrid: Espasa Calpe, pp. 25-38.

Mattoso, José (1993), História de Portugal, vol. II. Lisboa: Círculo de Leitores.

Panvini, Bruno (1994), Poeti italiani della corte di Federico II. Napoli: Liguori.

Ramos, Maria Ana (2011), "Chançons, va-t'ent sans perece / Au Boulenois di... Afonso III, um mecenas de colecções trovadorescas», en M. Calderón, J. Camões y J. P. Sousa (org.), «Por s'entender bem a letra». Homenagem a Stephen Reckert. Lisboa: Impr. da Casa da Moeda, pp. 489-509.

Rill, Bernd (1995), Sizilien im Mittelalter. Das Reich der Araber, Normannen und Staufer. Darmstadt: Wissenschaftliche Buchgesellschaft.

Riquer, Isabel de (2016), Historia literaria del infante Enrique de Castilla (1230-1303). Barcelona: Reial Acadèmia de Bones Lletres de Barcelona.

RiQuer, Martín de (1964), Història de la Literatura Catalana. Barcelona: Ariel. Vol. I.

Roncaglia, Aurelio (1982), «Le corti medievali», en A. Asor Rosa (dir.), Letteratura italiana, I. Il letterato e le istituzioni. Torino: Einaudi, pp. 33-147.

Runciman, Steven (1961), Visperas Sicilianas. Una historia del mundo mediterráneo a finales del siglo XIII. Madrid: Revista de Occidente.

Runciman, Steven (1973), Historia de las Cruzadas. Madrid: Alianza Editorial. 3 vols.

SERRÃo, Joaquim Veríssimo (1977), História de Portugal, vol. V. Lisboa: Ed. Verbo.

Sesma, José Ángel (2000), La Corona de Aragón. Una aproximación histórica. Zaragoza: Caja de Ahorros de la Inmaculada de Aragón.

Soldevila, Ferran (1950-1962), Pere el Gran. Barcelona: Institut d'Estudis Catalans, 3 vols.

SoldevilA, Ferran (1971), Les quatre grans cròniques. Barcelona: Edit. Selecta.

Soldevila, Ferran (1980), Jaume I. Pere el Gran. 3. ${ }^{\mathrm{a}}$ ed. Barcelona: Vicens-Vives.

VARVARO, Alberto (1987), «Il regno normanno-svevo», en A. Asor Rosa (dir.), Letteratura italiana, Storia e geografia, I. L'età medievale. Torino: Einaudi, pp. 79-99. 
Villacañas, José Luis (2003), Jaume I el Conquistador. Madrid: Espasa Calpe.

WillemSEn, Carl Arnold (1982), Bibliografia federiciana: fonti e letteratura storica su Federico II e gli ultimi svevi. Bari: Società di storia patria per la Puglia.

Recibido: $19 / 10 / 2021$

Aceptado: 22/11/2021

\section{$\cos 80$}

\section{LA EUROPA DE Alfonso X: FECHAS y PERSONAJES}

REsUMEN: El trabajo presenta un breve panorama de la segunda mitad del siglo XIII, tomando dos puntos de apoyo: por una parte, las grandes batallas que configuraron los límites de los reinos del occidente europeo hasta nuestros días; por otra, los reyes que participaron en una política de alianzas, cuya balanza estuvo en manos de la Iglesia y de Francia. La simplicidad del planteamiento, en un tema muy complejo, permite comprender las relaciones familiares y culturales del período en el que vivió Alfonso X.

Palabras-clave: Alfonso X. Felipe Augusto. Federico II y los Hohenstaufen. Luis IX de Francia. Carlos I de Anjou. Jaime I de Aragón. Pedro III de Aragón. Afonso III de Portugal. Teobaldo II de Navarra. Inocencio III. Urbano IV. Clemente IV. Inocencio IV.

\section{The Europe of Alfonso X: DATES AND Characters}

ABSTRACT: This work presents a brief overview of the second half of the 13th century, taking two points of support: on the one hand, the great battles that shaped the limits of the kingdoms of Western Europe up to the present day; on the other, the kings who participated in a policy of alliances, the balance of which was in the hands of the Church and France. The simplicity of the approach, in a very complex subject, allows us to understand the family and cultural relations of the period in which Alfonso X lived.

KeYwords: Alfonso X. Philip Augustus. Frederick II and the Hohenstaufen. Louis IX of France. Charles I of Anjou. James I of Aragon. Pedro III of Aragon. Afonso III of Portugal. Theobald II of Navarre. Innocent III. Urban IV. Clement IV. Innocent IV. 